\title{
LONG TERM ALTERATION OF IMMUNE FUNCTIONS FOLLOWING LOW LEVEL EXPOSURE TO SARIN IN RATS
}

\begin{abstract}
Jiř̌ Kassa ${ }^{1}$, Zuzana Kročován ${ }^{2}$, Josef Vachek ${ }^{1}$
Purkyně Military Medical Academy, Hradec Králové: Department of Toxicology ${ }^{1}$, Institute of Radiobiology and Immunology ${ }^{2}$

Summary: 1. Long term alteration of immune functions caused by low doses of nerve agent sarin were studied in rats exposed to sarin by inhalation. The alteration of immune functions by sarin was monitored by using two methods ( the evaluation of in vitro spontaneous as well as stimulated proliferation of spleen cells and in vitro bactericidal activity of peritoneal macrophages) at 3,6 and 12 months following sarin exposure. 2. The results indicate that not only symptomatic but also asymptomatic dose of sarin is able to alter some immune functions at six and twelve months following exposure to sarin. 3. Thus, not only organophosphorus insecticides but also nerve agents such as sarin can be potentially immunotoxic even at very low doses that do not cause clinically manifested intoxication following the inhalation exposure. The ability of sarin at low doses to alter immune functions seems to be really long term (up to 12 months following the exposure).
\end{abstract}

Key words: Sarin; Low level inhalation exposure; Immunotoxicity; Rat

\section{Introduction}

Nerve agents, highly toxic organophosphorus compounds (OPs) represent potential threats to both military and civilian population, as evidenced in recent terroristic attacks in Japan (12). The irreversible binding to and subsequent inactivation of acetylcholinesterase (AChE, EC 3.1.1.7), the enzyme that normally catalyzes the hydrolysis of acetylcholine ( $\mathrm{ACh})$ at neuromuscular junctions and other cholinergic synapses, is generally believed to be the major mechanism of OP poisoning. The accumulation of ACh in the cholinergic synapses causes the overstimulation of peripheral as well as central cholinergic nervous systems, clinically manifested as acute cholinergic crisis (convulsions, respiratory failure and/or death) $(8,18)$. In addition, OPs have many other effects that have an influence on various organs and systems of organs. They are called as nonspecific or non-cholinergic effects and involve the activation of multiple non-cholinergic neurotransmitter systems in the central nervous system (CNS), mutagenic, stressogenic, immunotoxic, hepatotoxic, membrane and hematotoxic effects (1).

Several studies on the immunotoxic effects of OP compounds in experimental animals have demonstrated the laboratory signs of immunosuppression such as a decreased number of cells in the spleen and thymus (5), an inhibition of chemotaxis in neutrophils (19) or inhibition of interleukin 2 production (2) following the exposure to OPs, especi- ally to organophosphorus insecticides (OPI). The immunotoxic effects of OPI has been also shown in humans but the evaluation of human immunotoxicity of OP compounds is limited to few studies. Lee and his co-workers were the first to draw attention to possible effects of OPs on human leucocyte function. They demonstrated that lymphocyte proliferation to phytohemaglutinin in vitro was decreased in the presence of OPs (6). Marked impairment in neutrophil chemotaxis and neutro phil adhesion and a reduction in the natural killer cell activity was observed in workers exposed to OPs $(3,11)$.

Much is known about the acute effects of nerve agents and less toxic OPI but there have been few studies of possible toxic effects of low level exposures. Therefore, research dealing with the evaluation of the influence of low level exposure to $\mathrm{OP}$ agents on various physiological functions including the immune functions in OP-exposed organisms is needed. The purpose of this study is to find out whether a nerve agent sarin is able to produce the alteration of immune functions following single or repeated low-level inhalation exposure in rats.

\section{Methods}

Male albino SPF rats weighing $180-220 \mathrm{~g}$ were purchased from Konárovice (Czech Republic). They were kept in an air-conditioned room and allowed to access to standard food and tap water ad libitum. Food as well as water were 
sterilized before their use. The rats were divided into groups of ten. Handling of the experimental animals were done under the supervision of the Ethics Committee of the Medical Faculty of Charles University and the Military Medical Academy in Hradec Králové (Czech Republic).

Rats were exposed to low concentrations of sarin (obtained from Military Technical Institute, Zemianské Kostolany, Slovak Republic) in the inhalation chamber for 60 minutes. Three low concentrations of sarin were used for the inhalation exposure of rats:

- concentration 1 resulting in no clinical signs or symptoms and erythrocyte AChE inhibition of $<20 \%$ following 60 minute inhalation exposure $(0.8 \mu \mathrm{g} / \mathrm{l})$ - LEVEL 1 .

- concentration 2 resulting in no clinical signs or symptoms but a moderate inhibition of erythrocyte AChE (about $20 \%)$ following 60 minute inhalation exposure $(1.25 \mu \mathrm{g} / 1)$ - LEVEL 2. This level was used for a single or repeated (three times per one week) exposure.

- concentration 3 resulting in mild clinical signs such as salivation and miosis without convulsions and an inhibition of erythrocyte AChE of $40-50 \%$ following 60 minute inhalation exposure $(2.5 \mu \mathrm{g} / 1)$ - LEVEL 3.

Three, six and twelve months following exposure to sarin, the rats were killed by exsanquination in total anaesthesia. Then a peritoneal rinsing was performed to obtain peritoneal macrophages and the spleen was removed to obtain spleen cells (lymphocytes). Two methods were used to evaluate the possible immunotoxicity of sarin in sarin-exposed rats:

- in vitro spontaneous or stimulated (by lipopolysaccharides = LPS or conca navalin $\mathrm{A}=$ Con $\mathrm{A}$ ) proliferation of spleen cells (lymphoproliferation).

Antigens or non-specific mitogens can active lymphocytes to proliferation. The synthesis of nucleic acid is possible to be measured by incorporated $\left[{ }^{3} \mathrm{H}\right]$ thymidine $(7,13)$. The spleen was aseptically removed from the experimental animals into washing medium (RPMI 1640 - Sigma, glutamin - ÚSOL Prague, Czech Republic, gentamycin Pharmacia Bulgaria, nonessential amino acides - ÚSOL Prague, HEPES - Sigma, sodium pyruvate - Sigma, 2-mercaptoethanol - Fluka) and homogenized, washed three times in washing medium. Cells were resuspended in cultivation medium (washing medium $+10 \%$ fetal calf serum - Sigma) and concentration was adjusted into $4 \times 10^{6}$ cells $/ \mathrm{ml}$. $200 \mu \mathrm{l}$ of this suspension was removed into 96 well plate and either mitogens (Con A $5 \mu \mathrm{g} / \mathrm{ml}$, LPS 20 $\mu \mathrm{g} / \mathrm{ml}$ ) or medium was added. The cells were incubated for 67 hours at $37{ }^{\circ} \mathrm{C}, 5 \% \mathrm{CO}_{2}$ and $100 \%$ humidity. After incubation the cells were pulsed with $1 \mathrm{mCi}\left[{ }^{3} \mathrm{H}\right]$ thymidine per well, incubated at $37{ }^{\circ} \mathrm{C}, 5 \% \mathrm{CO}_{2}$ and $100 \%$ humidity for 5 hours. Cells were harvested, scintilation solution was added and radioactivity was measured by Rackbeta 1219. LKB.

- in vitro evaluation of reactive nitrogen intermediates $(\mathrm{N}$ oxides) that reflect the bactericidal effects of peritoneal macrophages.
The peritoneal macrophages were removed from peritoneal cavity by cold PBS, three times washed by washing medium and resuspensed in cultivation medium in concentration $1 \times 10^{6}$ cells $/ \mathrm{ml}$. $200 \mu$ of cell suspension was transfered into 96-well plate and incubated for 24 hours at $37{ }^{\circ} \mathrm{C}, 5 \% \mathrm{CO}_{2}$ and $100 \%$ humidity. Cells were centrifugated at $2000 \mathrm{rpm}$ for 20 minutes after incubation. Nitrite was assayed using Griess reaction (10). Briefly, $50 \mu$ of culture supernatant was incubated with $50 \mu \mathrm{l}$ of $0.5 \%$ sulphanilamide - Merck, $0.05 \%$ naphtylethylene diamide dihydrochloride - Loba and $2.5 \% \mathrm{H}_{3} \mathrm{PO}_{4}$ - Lachema Brno at room temperature for 10 minutes. The absorbancy at 450 $\mathrm{nm}$ was measured on microplate reader - Dynatech MRX. The nitrite (N-oxides) amount was calculated from a $\mathrm{NaNO}_{2}$ standard curve.

The experimental data were compared with the control values obtained from the rats exposed to pure air instead of sarin. The normal distribution of data was tested using Shapiro-Wilks test. In the case of normal data distribution, the statistical significance was determined by the use of Student's t-test. When the distribution of data was not normal, Mann-Whitney U test was used to evaluate the statistical significance. The differences were considered significant when $\mathrm{p}<0.05$.

\section{Results}

The results of the study related to the evaluation of sarin-induced alteration of immune functions at 3,6 and 12 months following low level sarin inhalation exposure of rats are summarized in figures 1-4. Sarin-exposed rats did not show any clinical signs of intoxication at the time of the evaluation of immune functions and their body weights did no differ significantly from control values.

While no significant sarin-induced alteration of immune functions was found at three months following the inhalation exposure (Fig. 1-2, 4), ConA stimulated lymphoproliferation was significantly decreased $(p<0.05)$ at six months following the single exposure of rats to sarin at level 2 (Fig. 3) and the production of $\mathrm{N}$-oxides (macrophage activity) was significantly decreased $(\mathrm{p}<0.05)$ in comparison with the control values at six months following the inhalation exposure to sarin at level 1 (Fig. 4).

The changes in the monitored immune functions at twelve months following the exposure were the most dramatic. While the single exposure of rats to sarin at level 2 significantly reduced spontaneous as well as LPS stimulated lymphoproliferation $(\mathrm{p}<0.05)$, the repeated exposure of rats to the same level of sarin significantly increased spontaneous as well as stimulated (LPS, Con A) lymphoproliferation in comparison with the control values $(\mathrm{p}<$ 0.05 ) (Fig. 1-3). The exposure of rats to sarin at level 1 caused a significant decrease in LPS stimulated lymphoproliferation ( $p<0.05$ ) (Fig. 2). On the other hand, a significant decrease in the production of $\mathrm{N}$-oxides (macrophage activity) following the repeated exposure to sarin at the level 2 


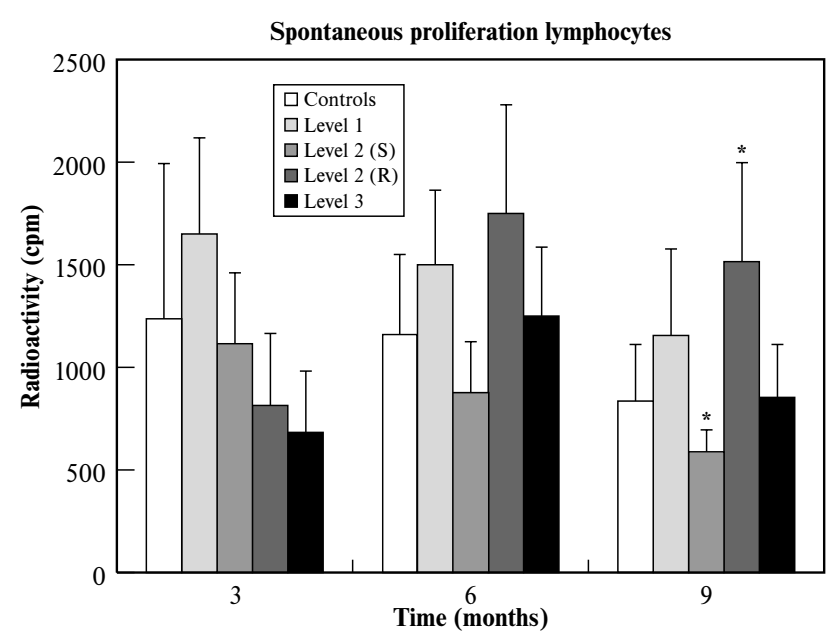

Fig. 1: The changes in spontaneous lymphoproliferation at three, six and twelve months following low-level sarin exposure of rats. Statistical significance: ${ }^{*} \mathrm{p}<0.05$.

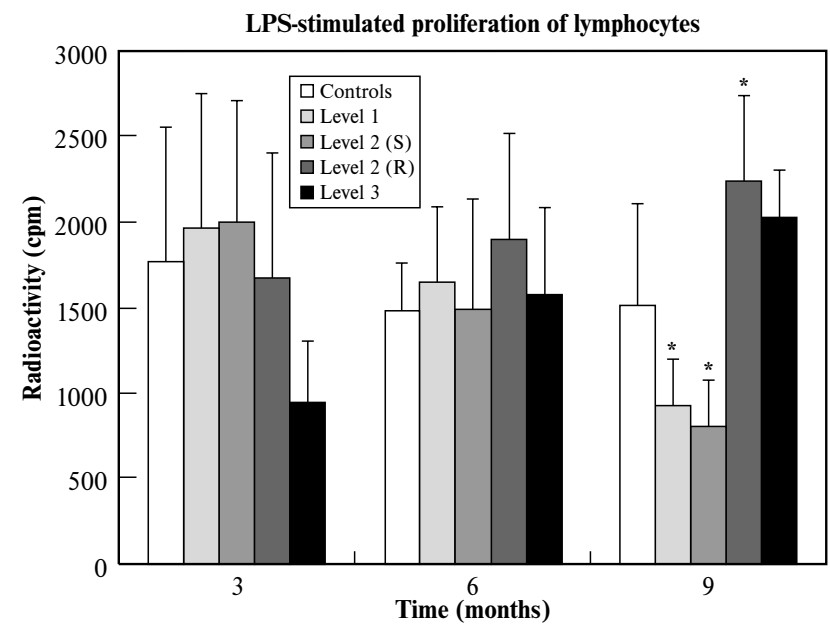

Fig. 2: The changes in LPS stimulated lymphoproliferation at three, six and twelve months following low-level sarin exposure of rats. For symbols - see Fig. 1.

and a significant increase in the production of $\mathrm{N}$-oxides following the single exposure of rats to sarin at the level 2 and 3 were demonstrated $(p<0.05)$ (Fig. 4).

\section{Discussion}

Clinical manifestations of exposure to OPs are extremely diverse. They primarily result from the inhibition of cholinesterase (ChE) activity, nevertheless, they also include several types of non-cholinergic effects such as genotoxic effects, teratogenic effects and immunosuppression $(9,17)$. The ability of OP compounds to induce an alteration of the immune system was primarily demonstrated in animals or humans exposed to OPI. Some results provide evidence that especially neutrophil function is altered in animals or

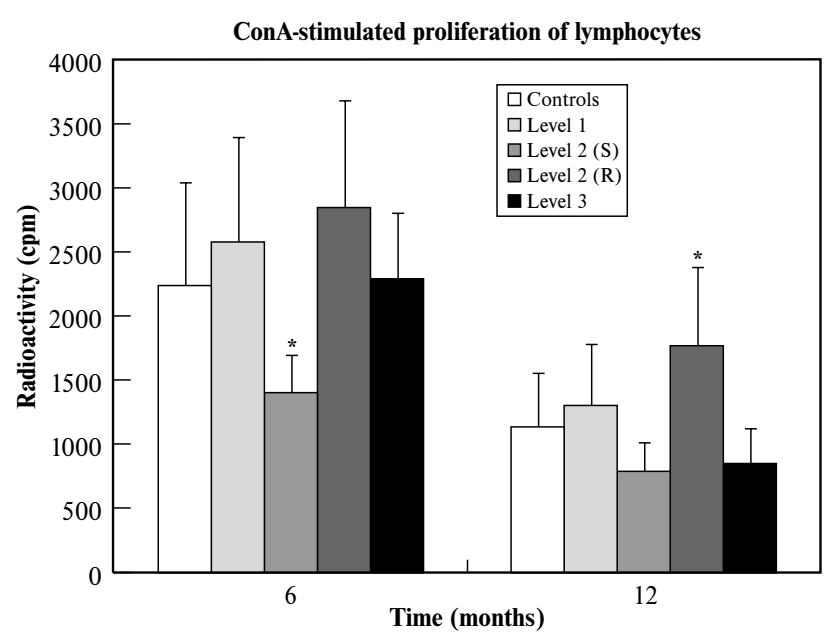

Fig. 3: The changes in Con A stimulated lymphoproliferation at six and twelve months following low-level sarin exposure of rat. For symbols - see Fig. 1.

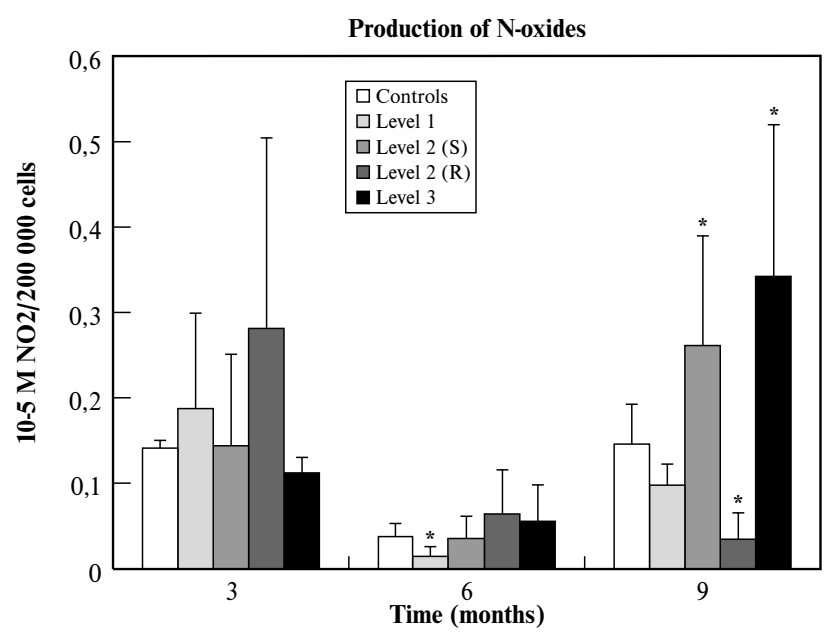

Fig. 4: The changes in the production of $\mathrm{N}$-oxides by peritoneal macrophages at three, six and twelve months following low-level sarin exposure of rats. For symbols - see Fig. 1.

humans exposed to OPI. In addition, the exposure to OPI may lead to changes in neutrophil function even in workers presenting no impairment in the ChE activity (14). Less is known about the immunotoxic effects of highly toxic OPs (nerve agents). Kant and co-workers documented a decrease in the weight of thymus, an important immune organ in severely affected soman survivors but other tests of immune function did not show differences between control and soman-exposed rats (4). Samnaliev described a decrease in the number of plaque forming cells in soman-exposed rats after the administration of sheep red blood cells as an antigen (16).

Our results confirm that not only symptomatic but also asymptomatic doses of nerve agent sarin are able to decrease the lymphoproliferation as well as the production of $\mathrm{N}$ - 
oxides, especially at twelve months following the exposure to sarin, although no dose-response or time-response was observed because of using really low doses of sarin. On the other hand, the increase in spontaneous as well as stimulated lymphoproliferation following the repeated exposure to asymptomatic dose of sarin and the increase in the production of N-oxides following the single exposure to asymptomatic or symptomatic dose of sarin were found at twelve months following the inhalation. The different effects of low-level sarin inhalation exposure on the proliferation of spleen cells and the bactericidal activity of peritoneal macrophages, especially at twelve months following the inhalation of sarin, is rather difficult to explain. These differencies can be caused by the compensatory reactions between immune functions studied. The increase in the spontaneous as well as stimulated lymphoproliferation following the repeated exposure to sarin at asymptomatic dose seems to represent the compensation of the decrease in activity of peritoneal macrophages and, on the contrary, the increase in the production of $\mathrm{N}$-oxides following the single exposure to sarin at asymptomatic as well as symptomatic dose seems to represent the compensation of the decrease in lymphoproliferation. Thus, the demonstrated increase in immune functions studied following the inhalation exposure to low-level sarin appears to be the result of compensatory reactions of immune functions rather than the result of direct effects of inhalation exposure to low-level sarin.

In conclusion, nerve agents such as sarin seem to be able to alter some immune functions in exposed rats at low, asymptomatic doses for a long time. However, it is not possible to compare this conclusion with literature data because no findings dealing with the influence of low doses of OP compounds on immune functions have been published till now. Our data confirm earlier reported finding that there are probably other protein targets very sensitive to some anticholinesterases including nerve agents which may represent a target for their low-level effects. However, the function of these protein targets is not known yet (15).

Although these findings are difficult to extrapolate directly to human low-level exposures to nerve agents, they indicate that subtle alteration of immune system could also occur in humans at exposures which do not cause any clinical manifestation.

\section{Acknowledgements}

The authors would like to thank Mrs. E. Vodáková, Mrs. J. Petrová, Mrs. E. Krejčová, Mrs. M. Kosková, Mrs. E. Trojanová and Mr. F. Dufek for their skilful technical assistance.
The study was supported by the grant of Ministry of Defense, No 66020397202.

\section{References}

1. Bajgar J. Biological monitoring of exposure to nerve agents. Br J Ind Med 1992;49:648-53.

2. Casale GP, Vennerstrom JL, Bavari S, Wang TL. Inhibition of interleukin 2 driven proliferation of mouse CTLL2 cells, by selected carbamate and organophosphate insecticides and congeners of carbaryl. Immunopharmacol Immunotoxicol 1993;15:199-215.

3. Hermanowitz A, Kossman S. Neutrophil function and infectious disease occupationally exposed to phosphoorganic pesticides: Role of mononuclear-derived chemotactic factor for neutrophils. Clin Immunol Immunopathol 1984;33:13-22.

4. Kant GJ, Shih TM, Bernton EW, Fein HG, Smallridge RC, Mongey EH. Effects of soman on neuroendocrine and immune function. Neurotoxicol Teratol 1991;13:223-8

5. Ladics GS, Smith C, Heaps K, Loveless SE. Evaluation of the humoral immune response of $\mathrm{CD}$ rats following a 2-week exposure to the pesticide carbaryl by the oral, dermal or inhalation routes. J Toxicol Environ Health 1994;42:143-56.

6. Lee TP, Moscati R, Park BH. Effects of pesticides on human leucocyte functions. Res Commun Chem Pathol Pharmacol 1979;23:597-609.

7. Ling NR, Kay JE. Lymphocyte stimulation. North - Holland Publishing Company 1975;p. 398.

8. Marrs TC. Organophosphate poisoning. Pharmacol Ther 1993;58:51-66.

9. Midtling JE, Barnett PG, Coye MJ. Clinical management of organophosphate poisoning. West J Med 1985;142:514-8.

10. Moncada S, Palmer RMJ, Higgs A. Nitric oxide: physiology, pathophysiology and pharmacology. Pharmacol Rev 1991;43:109-42.

11. Newcombe DS, Esa AH. Immunotoxicity of organophosphorus compounds. In: Newcombe DS, Rose NR, Bloom JC (eds): Clinical Immunotoxicology. New York: Raven Press, 1992:349-63.

12. Ohtomi S, Takase M, Kumagai F. Sarin poisoning in Japan. A clinical experience in Japan Self Defense Force (JSDF) Central Hospital Int Rev Arm For Med Ser 1996;69:97-102.

13. Pospíšil M, Drábek P, Hofman J, Nouza K, Klapáčová J. Effect of immunosuppressive agent on the blastogenic response of mouse spleen T and B lymphocytes. Folia Biol 1978;24:185-98.

14. Queiroz MLS, Fernandez MD, Valadares MC. Neutrophil function in workers exposed to organophosphate and carbamate insecticides. Int J Immunopharmacol 1999;21:263-70.

15. Ray DE. Chronic effects of low level exposure to anticholinesterases - a mechanistic review. Toxicol Lett 1998;102-103:527-33.

16. Samnaliev I, Mladenov K, Padechky P. Investigations into the influence of multiple doses of a potent cholinesterase inhibitor on the host resistance and humoral mediated immunity in rats. Voj Zdrav Listy 1996;65:143-7.

17. Sullivan JB. Immunological alterations and chemical exposure. Clin Toxicol 1989;27:311-43

18. Taylor P. Anticholinesterase agents. In: Hardman JG, Limbird LE (eds): The Pharmacological Basis of Therapeutics, $9^{\text {th }}$ ed. New York: McGraw Hill, 1996:161-76.

19. Ward PA. Chemotaxis of mononuclear cells. J Exp Med 1968;128:1201-21.

Submitted February 2000.

Accepted June 2000.

Doc. MUDr. Jiř́i Kassa, CSc., Purkyně Military Medical Academy, P.O. Box 35/T, 50001 Hradec Králové, Czech Republic. e-mail: kassa@pmfhk.cz 